\title{
Person-Oriented Conception of Happiness as the Ultimate Psychological Theory: Ten Main Reasons
}

\author{
Leonid Zigfridovich Levit \\ Centre for Psychological Health and Education, Minsk, Belarus
}

\section{Email address:}

leolev44@tut.by

\section{To cite this article:}

Leonid Zigfridovich Levit. Person-Oriented Conception of Happiness as the Ultimate Psychological Theory: Ten Main Reasons. Psychology and Behavioral Sciences. Vol. 6, No. 5, 2017, pp. 118-121. doi: 10.11648/j.pbs.20170605.17

Received: April 19, 2017; Accepted: May 5, 2017; Published: October 22, 2017

\begin{abstract}
The present work gives in brief ten main arguments in favor of the Person-Oriented Conception of Happiness $(\mathrm{POCH})$ as the main candidate to the role of the ultimate theory in modern psychology. Dual system and multilevel construction of POCH enables a bigger volume of material investigated, gives the opportunity for the scientist to occupy different positions for monitoring and analysis. POCH also covers heights and depths in the investigation - from studying biological predispositions of psychic phenomena up to acme of the human spirit.
\end{abstract}

Keywords: Altruism, Egoism, Individuality, Personality, Self-realization, Systemic Approach, Ultimate Theory

\section{Introduction}

According to many contemporary scientists, modern psychology strongly needs fundamental conceptions and metaphors, which can unite different schools and methods. Natural sciences - physics for example - also have the goal of constructing a coordinated, comprehensive and an allround theory with unlimited application. To make it possible, scientists hope to discover some simple general laws, which could fully explain the world [1]. In psychology, such a theory could answer the main questions about human nature. This paper outlines the main arguments in favor of our own, dual system and multilevel conception. Our optimism is based on its strong foundation, wide possibilities for explanations and a clear direction for future research.

\section{Person-Oriented Conception of Happiness: A Brief Description}

In the years 2006-2012, a synthesizing conception has been developed, which is based on the ideas of systemic approach and combines biological, psychological, social and spiritual (the highest) level of individual life and activity. The results of this ten-year work on the problem are summarized in seven monographs and plenty of articles [2-10].
The Person-Oriented Conception of Happiness (POCH) originally belongs (at least, partly) to eudaimonic group of theories, which deal with a person's realization of her own potential. It represents the interaction of two systems "Personal Uniqueness" (PU) and "Egoism" (EG).

Moving bottom-up, let us briefly describe the main components of POCH. Each system consists of four levels. Each level represents a certain period of a person's life from her birth until mature self-realization. Both systems develop from one level to the higher one, thus changing the interaction of horizontally corresponding levels, each of which is connected to this or that type of life problems.

Firstly, let us present the Personal Uniqueness system. PU is somewhat analogous to daimon in its classical meaning or personal potential in humanistic comprehension. Personal Uniqueness represents synthesis of individual gifts and potentials ("U") with the personal components ("P") that facilitate its application in "appropriate" activity. At its first biological level PU system is represented by the letter " $U$ " (Uniqueness), which implies a kind of natural gift, the inherited disposition of an individual. At the next second level, which is usually associated with a person's youth, the disposition gradually changes and abilities begin to actualize. At that very period, a young man usually has some difficulties due to the shortage of his personal maturity and responsibility. The situation is being corrected at the third stage, when the person acquires motivational components of 
self-regulation ("P") which help to overcome the obstacles inside specific activity and persistently move towards the attainment of personal goals. At the final fourth stage, (if it comes) we can see the mature Personal Uniqueness. Its realization provides all the "eudaimonic" effects, which will be discussed later.

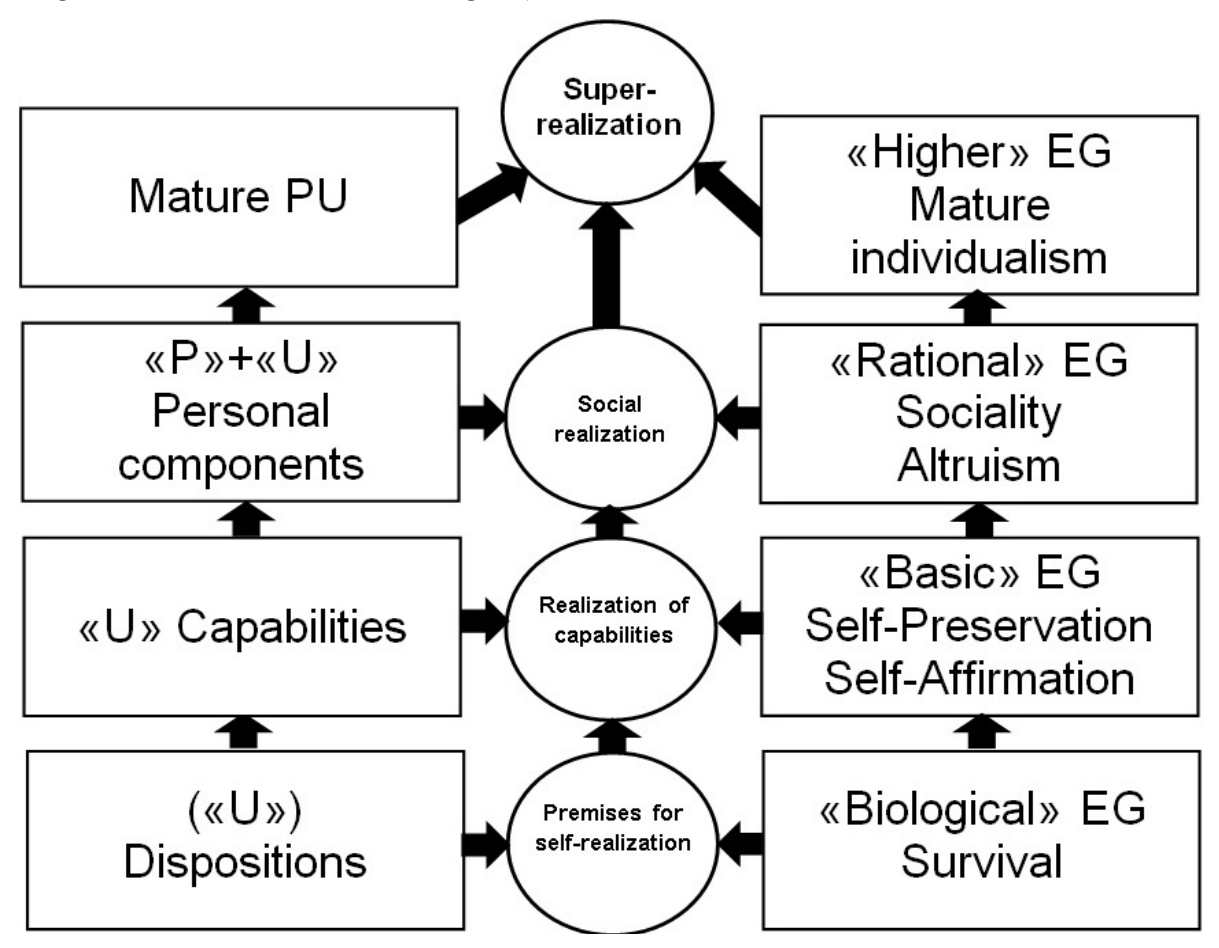

Figure 1. Schematic view of POCH.

Now let us describe the "Egoism" (EG) system. The biological ("body") level of our model (EG-1) relates to the instinct of self-preservation. Its good functioning results in the absence of essential body "problems" during selfrealization. The body level supplies a person with physical energy and gives opportunities to strive for optimal life. The necessity of its inclusion is determined by the importance of biological, genetic premises of person's egoism.

The concept of "Basic" Egoism (EG-2 is rather close to Freud's Id. EG-2 is primarily responsible for satisfying two basic instincts - food and sexual, that brings to a person some "fundamental" pleasures.

Moving further up along L2, EG-2 gradually transforms into "Rational" Egoism (REG). In general, REG is responsible for a person's successful activity at the social level and "higher", "human" pleasures.

The internal logic of our theory rests upon the following isomorphism: REG originates from EG in the same way as consciousness and rational mind allowed the humanity to evolve from the animal world. In connection with this, let us recall the Freud's idea that personality Ego is developing from Id [11].

Finally, the fourth level is associated with higher forms of egoism (mature individualism), when a person, having surmounted the three previous stages, makes a decision to devote her life to unique self-realization. Here we can see the overcoming of the lower, Basic Egoism with its pleasure principle and the serious reorientation of Rational Egoism on the third level. While REG organizes the social environment for an individual, her "Higher" Egoism creates the best conditions for the PU actualization.

Thus, it can be argued that cohesive interaction of EG-4 and PU (inborn gifts and talents) brings self-realization and complete human life. The "Higher" Egoism is the best partner for "Personal Uniqueness" system since it accomplishes protective and motivating functions in the process of her actualization, being on the outside of the PU specific activity. At the same time, EG-4 doesn't lose connection with the whole Egoism system - its energy and other resources. To put it metaphorically, the "Higher" EG can be described as the experienced "promoter", which protects his very talented pupil (PU) from external threats and superfluous problems in the time of her actualization.

One of the most interesting things about POCH is that EG at its highest stages, being "Basic" EG "offspring", becomes rather antagonistic towards his "father" for the sake of PU actualization. Thus, a person faces an existential choice: to stay on the "hedonic" level, or to "climb higher", discover her true potentials and lead a meaningful life. She has to choose between life for oneself (the second and the third level of the "EG" system) and life in the name of oneself (the fourth level of both systems).

At first, we positioned $\mathrm{POCH}$ as one of the eudaimonic conceptions in the modern positive psychology [2], [3]. However, very soon we discovered much broader scientific scope for our theory.

In this summarizing paper, we present ten main proofs which corroborate POCH ability to be the final (most general and fundamental) theory for modern psychology. 


\section{The Advantages of POCH as the Ultimate Psychological Theory}

1. The dual system construction of POCH enables a scientist with a much more solid, "binocular" vision of the material under investigation. The dualistic approach helps an explorer to occupy various positions for observation and analysis. Monistic methods, which prevail in science, are usually unable to explain numerous shades of an object, to see it from different points of view. For example, the nature of electron can be explained satisfactorily only within a dualistic frame.

2. Besides two interacting systems, POCH also possesses the multilevel construction. Such peculiarity provides "height" as well as "depth" of exploration, which extends from the analysis of biological dispositions of the psychic phenomena up to acme of human spirit.

3. The above-mentioned advantages of $\mathrm{POCH}$ are best seen in a comparative analysis with other philosophical and psychological theories [3], [4]. Our theory can also be used with larger objects - such as the whole country at a certain stage of development [10].

4. Two global concepts - "Egoism" and "Personal Uniqueness" - are put into the foundation of each POCH system. The first term delineates the original commonness between people, while the second concentrates at their individual differences. With such a method, nothing important can be lost.

5. The dual system structure of POCH grasps the dualistic nature of psychology itself, which is directed to natural as well as to humanitarian sciences with their different modes of discourse. While the "Egoism" system having biological roots gravitates towards natural sciences, the "Personal Uniqueness" system looks more like a "humanistic" concept. Thus, studying the successful interaction between "EG" and "PU" systems creates various opportunities for closing in of both methods within psychology.

6. POCH levels, being represented as the corresponding periods of human life, enable to explore it from the prenatal stage up to at least $70-75$ years. Thus, the ontological "satiation" of POCH becomes important for the developmental psychology.

7. We are convinced that the "egoism" concept can be the most appropriate systemic factor for the common scientific hierarchy (biological - psychological social). From the biological point of view, egoism of the species means survival. In psychology, egoism reverberates person's preference of her own interests and desires. Egoism at the social level is also widely represented (group egoism, reciprocal altruism etc.). Naturally, levels 1-3 of the "Egoism" system in $\mathrm{POCH}$ imply the ideas of the above-mentioned sciences.

8. Egoism as the new object of studying in psychological science seems a more appropriate concept than "soul" or "psychic activity". According to the well-known doctrine of psychological egoism, the only deeprooted foundation (as well as the final goal) for which a person strives is her own interest. Taken in this aspect, egoism points the way of further investigations (since people's interests and desires always have a direction). In this case, psychology acquires the initial trend that corresponds to the inborn human nature. The "subject soul" substitutes the "substance soul".

9. In our experimental and theoretical work we have cleared up the link between POCH categories and some other "global" concepts which constitute the essence of human values - with altruism [6], meaning [5], basic motivation [8], spirituality [8], happiness [9] etc.

10. Our theory points the "first-grade" way of living for a modern citizen - eudaimonia, interpreted as the process of the discovery, development and actualization of a person's unique potential. Eudaimonia is best described through the productive interaction of the both POCH systems.

11. Some conclusions made from our work are important for other sciences and practices. For example, a specialist in pedagogics may teach her pupils to see their own good while helping other people. They may also learn to realize benefits for the whole society in a broader context while pursuing their own interests. Anyway, the situation becomes much more suitable for creative innovations. In the sphere of moral philosophy, the notion of altruism loses its initial purity because of its origination from and positive connection with egoism.

\section{POCH: Two Main Counterarguments and the Discussion}

Here we present two possible critical remarks (one for each system of $\mathrm{POCH}$ ) and then refute them.

1. The notion of egoism arouses mostly negative associations.

Counterargument. Such associations were traditional for the Soviet and are still typical for the Post-Soviet psychologists due to the rules of the collectivist totalitarian society. However, the traditions change gradually.

Besides, multilevel construction implies that one can choose between different forms of egoism. Each higher level of the "Egoism" system has more positive connotations than the previous one. At its highest (the fourth) level of development, egoism's nature is transformed to such an extent that PU realization becomes its main priority. In our opinion, people should not try to get rid from their egoism this is impossible. However, they can make choice in favor of its higher forms, which are connected with individual selfdevelopment and self-realization.

2. Few people possess Personal Uniqueness (which is interpreted as an individual "talent"). Can such an 
inequality lead to discrimination?

Counterargument. A scientist should deal with facts and should not propagate positive illusions. Otherwise, psychology will lose its scientific status. The facts tell that nature is unfair in the distribution of her gifts. The protective measures against the inborn inequality should provide equal initial opportunities for self-realization for all the citizens in full congruence with their equal human rights. Sociologists and economists, not psychologists, should work out other compensational mechanisms for the less successful individuals.

\section{Conclusion}

It should be mention that despite all efforts, the author has not found any other psychological theory, which possessed all POCH advantages. We even have not found a theory whose explanatory power is based on the interaction of two developing systems. It is understood, the author will be grateful for any feedback and critical remarks. Meanwhile, we proudly present our Person-Oriented Conception of Happiness as the main candidate to the role of the ultimate (most fundamental and general) theory in modern psychology.

\section{References}

[1] Weinberg S. Dreams of a Final Theory. New York: Vintage Books, 1992.

[2] Levit L. Z. Happiness: Person-Oriented Conception //
International Journal of Advances in Psychology. Vol. 1. Iss. 3. November, 2012. Pp. 46-57.

[3] Levit L. Z. Person-Oriented Conception of Happiness: Between Freud, Jung and Maslow // International Journal of Economy, Management and Social Sciences. 2013. August. № 2 (8). Pp. 576-584.

[4] Levit L. Z. Person-Oriented Conception of Happiness and Some Personality Theories: Comparative Analysis // SAGE Open. January-March, 2014. Published 10 January, 2014. Pp. 1-7.

[5] Levit L. Z. Meaning and Egoism: Are the Notions Compatible? // International Journal of Social Science Research. 2014. Vol. 2. № 1. - Pp. 102-112.

[6] Levit L. Z. Egoism and Altruism: the «Antagonists» or the «Brothers»? // Journal of Studies in Social Sciences. 2014. Volume 7. № 2. - Pp. 164-188.

[7] Levit L. Z. Personal Uniqueness Therapy: Living with an Inner Ideal. // American Journal of Applied Psychology. Vol. 3. № 1, January 2014. Pp. 1-7.

[8] Levit L. Z. Individual Potential and Its Realization: the Dual System Theory (in two books). - Minsk: RIVSH Publishing House, 2014.

[9] Levit L. Z. Exploring the Psychology of Happiness: The Latest Experimental Results // Psychology and Social Behavior Research. 2015. № 3 (1). Pp. 1-10.

[10] Levit L. Z. The Ukraine: is the Mission Possible? // Spring Readings (Scientific Conference). Kiev: the Centre for Scientific Publications, 2015. Pp. 95-98.

[11] Freud Z. Beyond the Pleasure Principle. Tbilisi: Merani, 1991. 